\title{
LA IGLESIA DE SAN GIL DE GUADALAJARA
}

\author{
Antonio Miguel Trallero Sanz \\ Universidad de Alcalá
}

\begin{abstract}
Guadalajara contó desde la Edad Media con diez parroquias. La mayoría de sus templos seguían la tradición constructiva islámica adaptada a las corrientes arquitectónicas cristianas, es decir, según el denominado "estilo mudéjar". En el siglo XIX, el número de parroquias se redujo a cinco y posteriormente a cuatro. La última suprimida fue la de San Gil, que fue demolida en 1924. En ese momento se salvaron la portada y una capilla por considerarse que eran los únicos elementos del primitivo templo, para ser demolidos que en 1931. A pesar de ello, se conservó parte del ábside. Gracias a estos restos y al estudio de una serie de documentos gráficos conservados, se llega a la conclusión de que el templo demolido era una edificación "mudéjar", que sin ser demolido, fue sometido en el siglo XVII a una profunda trasformación que le privó de su aspecto primitivo.
\end{abstract}

Palabras clave: Mudéjar; Capilla; Yesería; Parroquia.

\section{THE CHURCH OF SAINT GILES IN GUADALAJARA}

From the time of the Middle Ages Guadalajara had ten parishes. Most parish churches were constructed following the Islamic architectural tradition adapted to Christian architectural trends, that is to say, according to the style known as Mudéjar. In the 19th century, the number of parishes was reduced to five and then to four. Saint Giles was the last parish suppressed, and finally demolished in 1924. At that moment, the doorway and a chapel were preserved because they were considered to be the only elements of the original temple, but they were demolished in 1931. Nonetheless, part of the apse was saved. Thanks to these remains, and the study of a series of graphic documents, it is possible to conclude that the demolished temple was indeed a Mudéjar building. In the $17^{\text {th }}$ century the church underwent a major transformation that resulted in the loss of its original appearance, but the medieval structure survived beneath the exterior renovation.

Key words: Mudéjar; Chapel; Plasterwork; Parish.

\section{Los templos de la Guadalajara medieval}

Tras la reconquista de la ciudad de Guadalajara en 1085 durante el reinado de Alfonso VI, como en el resto de Castilla, una primera etapa se caracterizó por una tolerancia con respecto a la población musulmana, sin embargo, a partir del reinado de Fernando III la política se orientó fa- 
voreciendo a la población cristiana. Esta nueva orientación se percibe claramente en el fuero otorgado a la ciudad de Guadalajara en $1219^{1}$.

La ciudad medieval se organizó construyendo un entramado parroquial en el que cada Iglesia y "collación" (parroquia) era además una célula municipal de tributación fiscal y de encuadramiento militar, completándose con un importante número de Monasterios construidos dentro y fuera de las ciudades.

En Guadalajara esta organización se hizo con diez parroquias: San Andrés, San Julián, Santo Tomé, San Esteban, San Miguel, Santa María, San Ginés, San Gil, San Nicolás y Santiago.

En los primeros años del siglo XIX (1831) debido a la falta de recursos y a la disminución de la población de la ciudad de Guadalajara que llego a reducirse a 1700 vecinos, se suprimieron cinco de las diez parroquias primitivas, la de San Andrés, San Julián, Santo Tomé, San Esteban y San Miguel, y posteriormente la de San Gil, quedando reducidas a las de Santa María, San Ginés, San Nicolás y Santiago.

De las cinco suprimidas se mantuvieron en un principio abiertas al culto las de San Andrés, Santo Tomé, como santuario de la Virgen de la Antigua y San Esteban, como Convento de Jerónimas ${ }^{2}$, demoliéndose las de San Julián y San Miguel. Posteriormente se demolió San Andrés y San Esteban y del antiguo templo de Santo Tomé únicamente se conservó su cabecera. En cuanto a las parroquias que se mantuvieron, la mayor parte de ellas de trasladaron a los templos de los Conventos suprimidos ${ }^{3}$ demoliéndose los templos primitivos.

Debido a los condicionantes históricos y culturales de la ciudad, y también como consecuencia de los materiales constructivos existentes en la zona ${ }^{4}$, la mayor parte de las Iglesias, junto con el resto de las edificaciones, se levantaron siguiendo la tradición constructiva islámica adaptada a las corrientes arquitectónicas cristianas, es decir según el denominado "estilo mudéjar".

De las Iglesias medievales de Guadalajara de "estilo mudéjar", únicamente se ha conservado, aunque muy transformado, un templo parroquial, Santa María, y un templo conventual, Santa Clara, actual parroquia de Santiago, habiéndose conservado también restos de otras dos Iglesias, San Gil y Santo Tomé.

El paisaje urbano de Guadalajara en el siglo XVI queda reflejado en la vista realizada por Van der Wyngaerden en 1565 en la que están representados los templos de la ciudad ${ }^{5}$. En la vista realizada un siglo después por Pier Marie Baldi $(1668)^{6}$ se aprecia la transformación experimentada. Junto con la construcción de nuevos edificios de mayores dimensiones, son visibles las reformas llevadas a cabo en los antiguos templos, los que en estos años se vieron sometidos a unos procesos de "barroquización", tanto interior como exterior mediante la construcción de chapiteles como remates de sus torres.

La destrucción del patrimonio religioso durante los siglos XIX y XX supuso la transformación del paisaje urbano de la ciudad.

Por medio del presente trabajo se pretende llegar a conocer la traza y el sistema constructivo del primitivo templo parroquial de San Gil en Guadalajara partiendo de los restos que todavía se mantienen, del estudio de los templos existentes y del análisis de la documentación conservada.

Con respecto a la documentación conservada, mientras la escrita ha sido objeto de diferentes

\footnotetext{
${ }^{1}$ Ortiz, 1996.

2 Tras la supresión de la Parroquia de San Esteban, esta Iglesia y unas casas anejas sirvieron de Convento de Jerónimas, trasladándose esta congregación desde el Convento de los Remedios en la actual Plaza de los Caídos.

${ }^{3}$ San Ginés fue trasladado al templo conventual de Santo Domingo, Santiago a la Iglesia Conventual del Convento de Clarisas y San Nicolás al templo de la Santísima Trinidad del Colegio de Jesuitas.

${ }^{4}$ Trallero, 1998: 27-43.

5 Vista de Guadalajara. Van der Wyngaerden, 1565.

${ }^{6}$ Vista de Guadalajara. Pier Marie Baldi,1668. Biblioteca Laurenziana de Florencia.
} 
estudios, la gráfica, por lo general no ha sido suficientemente analizada y sin embargo, puede facilitarnos muchos datos necesarios para llegar a conocer estas edificaciones.

Para ello se han utilizado fundamentalmente los fondos del Archivo General de la Administración, el Histórico Provincial y el Municipal de Guadalajara.

Han sido especialmente importantes los proyectos y planos conservados en el Archivo Municipal de Guadalajara o el Plano y documentos complementarios del levantamiento de Guadalajara del Instituto Geográfico y Estadístico, así como los archivos fotográficos del Centro de la Fotografía y la Imagen Histórica de Guadalajara (CEFIHGU) de la Diputación de Guadalajara. Se han utilizado también catálogos de exposiciones e incluso revistas de la época.

\section{San Gil}

\section{Antecedentes históricos}

Con respecto a la fundación de la Parroquia de San Gil existe una referencia según la cual existía antes de 1226, que es la noticia más antigua de todas las parroquias de la ciudad ${ }^{7}$, aunque probablemente el templo objeto del estudio sea contemporáneo, quizás algo posterior, al de Santa María, con el que guardaba muchas semejanzas.

Esta parroquia, probablemente por su proximidad a la Plaza Mayor tuvo una gran importancia durante la Edad Media por haber sido la sede de las reuniones del Concejo antes de la construcción del edifico municipal.

No fue esta una de las cinco primeras parroquias suprimidas, desconociéndose con exactitud en que año se produjo. Ya en 1906, el párroco de S. Nicolás es quien la representa ante el Ayuntamiento solicitando licencia para obras estructurales que afiancen su fábrica por la condición de ser San Gil su iglesia auxiliar.

Las negativas reiteradas por parte del Ayuntamiento para otorgarle estas licencias concluyen en 1921, primero con un acuerdo de proposición al Arzobispo de Toledo de compra del inmueble para su demolición atendiendo a la utilidad del vecindario "...para ensanche de la vía pública o para los fines que el Ayuntamiento acuerde", y segundo con el acuerdo de su demolición: "...se haga por administración el derribo de la iglesia de San Gil con fin de dar trabajo a la clase obrera", siendo su alcalde presidente D. Miguel Solano.

No obstante, estos acuerdos no se cumplirían hasta el verano de 1924, cuando tras producirse un desplome parcial del atrio se procedió urgentemente a su derribo, en el transcurso de estos trabajos se emitió la Real Orden de 22 de Agosto de1924, de declaración de Monumento Histórico Artístico ${ }^{8}$.

En ese momento quedaba todavía en pie la Capilla de los Orozco y la puerta principal, que tras varios intentos de restauración y conservación, ${ }^{9}$ se demolería también en 1931. Se salvó únicamente el muro perimetral del ábside, no por reconocimiento de su interés arquitectónico sino por ser medianero con otra finca y no ser posible su demolición sin afectar a la finca colindante. También se recogieron los restos de la decoración mudéjar de esta Capilla, guardados hoy en la cámara de la de Luis de Lucena, en Guadalajara.

\footnotetext{
${ }^{7}$ Pradillo, 1994: 214-215.

${ }^{8}$ Oficio de traslado del Subsecretario del Ministerio de Instrucción Pública y Bellas Artes de Real Orden por la que se declara Monumento Arquitectónico-Artístico la iglesia de San Gil de Guadalajara. Real Academia de la Historia. Exp: CAGU/9/7956/19(2).

9 Expediente sobre el derribo de la Iglesia de San Gil quedando subsistentes la capilla mudéjar y la portada. Real Academia de la Historia. Exp. CAGU/9/7956/19(6).
}

Arch. esp. arte, LXXXVIII, 350, ABRIL-JUNIO 2015, 113-130

ISSN: 0004-0428, eISSN: 1988-8511, doi: 10.3989/aearte.2015.07 


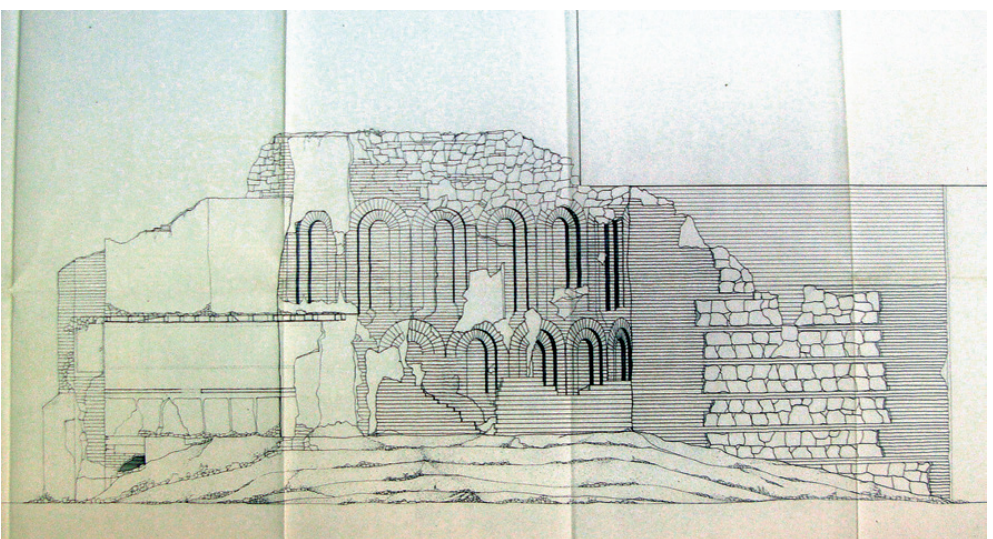

Fig. 1. Iglesia de San Gil. Alzado exterior del ábside tras la demolición del edificio adosado. Proyecto de restauración del ábside de San Gil. AMG.

\section{Restos conservados}

De esta Iglesia, hoy desaparecida, situada en la actual Plaza del Concejo de Guadalajara únicamente se conservan unos mínimos restos, actualmente restaurados, que se salvaron casi milagrosamente por encontrarse adosados a otra edificación hoy demolida.

Tras la demolición del edificio adosado quedaron liberados los restos del muro del ábside que fueron posteriormente restaurados ${ }^{10}$.

Estos restos consisten en un muro curvo que corresponde al antiguo ábside del templo, un muro recto situado a la izquierda del anterior, con tres huecos superpuestos, que corresponde aunque mutilada a la cabecera de la antigua capilla de los Orozco, y otro muro recto y un arco reconstruido, situado a la derecha del ábside, que servía de cerramiento de la sacristía (fig. 1).

El muro del ábside que se ha conservado es semicircular. Está decorado exteriormente con tres hiladas de arcos, alternadas entre sí, rematadas superiormente por medio de una cornisa corrida. En la hilada central de arcos existen tres huecos que servían de iluminación a la cabecera del templo. A este muro le falta el cuerpo superior.

Está realizado en ladrillo sobre zócalo de piedra caliza procedente de los páramos alcarreños, hoy no apreciable por encontrarse bajo el nivel actual del terreno.

Los dos muros rectos conservados están realizados con mampostería y machones de ladrillo. Parte de esta mampostería fue colocada durante la restauración de estos restos.

El aspecto que presenta el muro del ábside hacia el interior es de hiladas de ladrillo y mampostería de piedra caliza, y unos recercados de ladrillo en los huecos de iluminación, todo ello ejecutado durante su restauración.

Recientemente al muro que servía de remate a la capilla de los Orozco se le han añadido unas pinturas, ya previstas en el proyecto de restauración primitivo, que sirven para recordar a las antiguas yeserías que la recubrían interiormente, yeserías de las que como veremos más adelante, se conservan unos pequeños restos en la Capilla de Luis de Lucena, antigua capilla de Nuestra Señora de los Ángeles que se ha conservado de la también desaparecida Iglesia de San Miguel (fig. 2).

\footnotetext{
${ }^{10}$ Proyecto de Restauración del ábside de San Gil. 4-VII-82. Archivo Municipal de Guadalajara (AMG).
} 


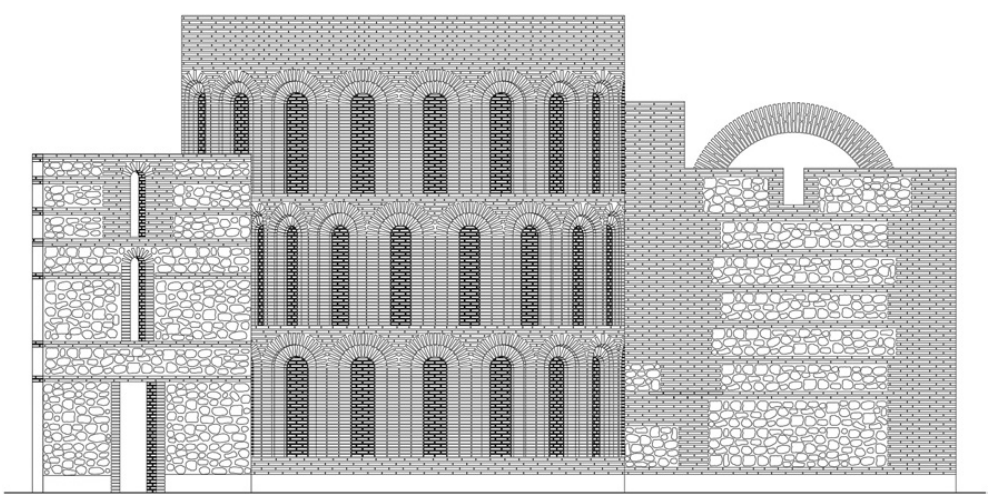

Fig. 2. Restos de la Iglesia de San Gil. Alzado exterior. Fernando de la Vega Todolí con la dirección de Antonio M. Trallero.

\section{Documentación gráfica existente}

Además de los restos conservados, existe una serie de documentos que han sido fundamentales para llegar a conocer esta Iglesia.

El documento gráfico más antiguo es la vista de Guadalajara de Antón Van der Wytngaerde de 1565, en ella aparece representada la Iglesia de San Gil, destacando su torre por encima del caserío de la ciudad.

Como para otros edificios, para conocer la Iglesia de San Gil ha sido fundamental el plano de la ciudad de Guadalajara realizado a escala 1/1000 por el Instituto Geográfico y Estadístico, bajo la dirección de Ibáñez Ibero en 1880 que recoge las planta de la mayoría de los edificios públicos de la ciudad.

De este, como del resto de los edificios representados, se realizó una ficha, en la que se leen las dimensiones recogidas en la toma de datos. Este documento, junto con el levantamiento de los restos conservados, ha sido fundamental para dibujar nuevamente la planta del edificio (fig. 3).

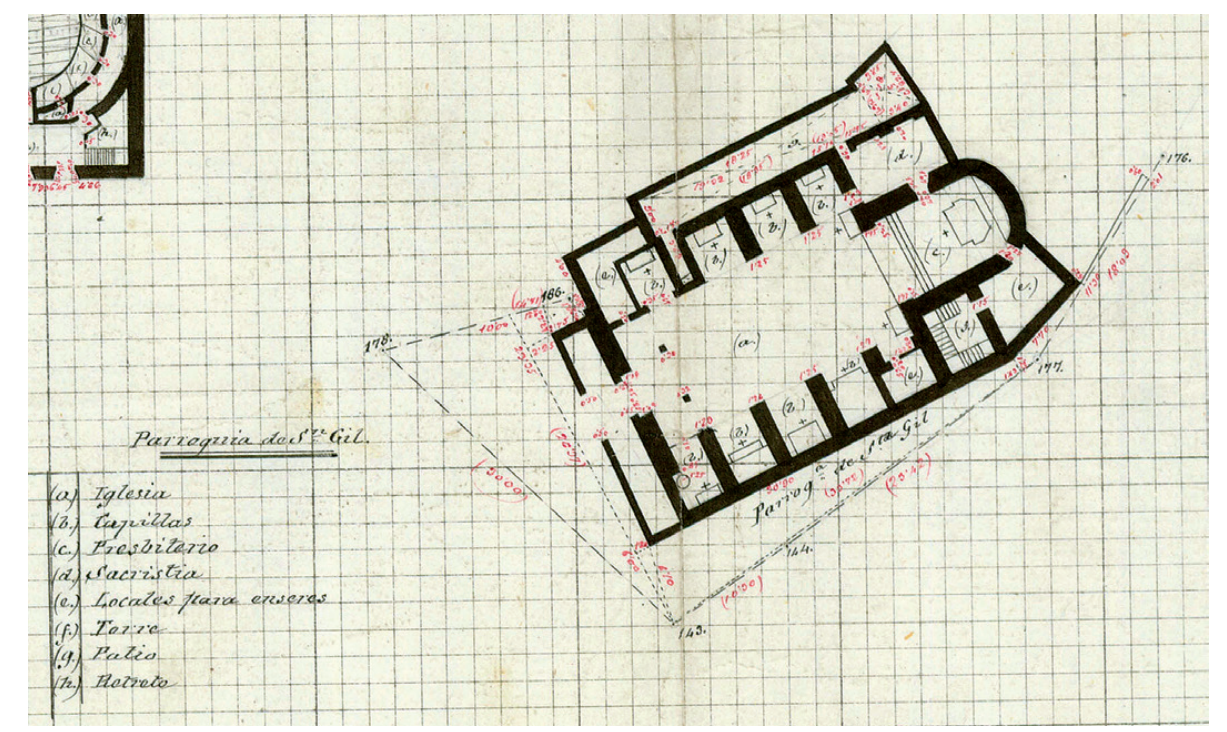

Fig. 3. Plano realizado por el Instituto Geográfico y Estadístico con las plantas de alguna de las Iglesias de Guadalajara.

Arch. esp. arte, LXXXVIII, 350, ABRIL-JUNIO 2015, 113-130

ISSN: 0004-0428, eISSN: 1988-8511, doi: 10.3989/aearte.2015.07 


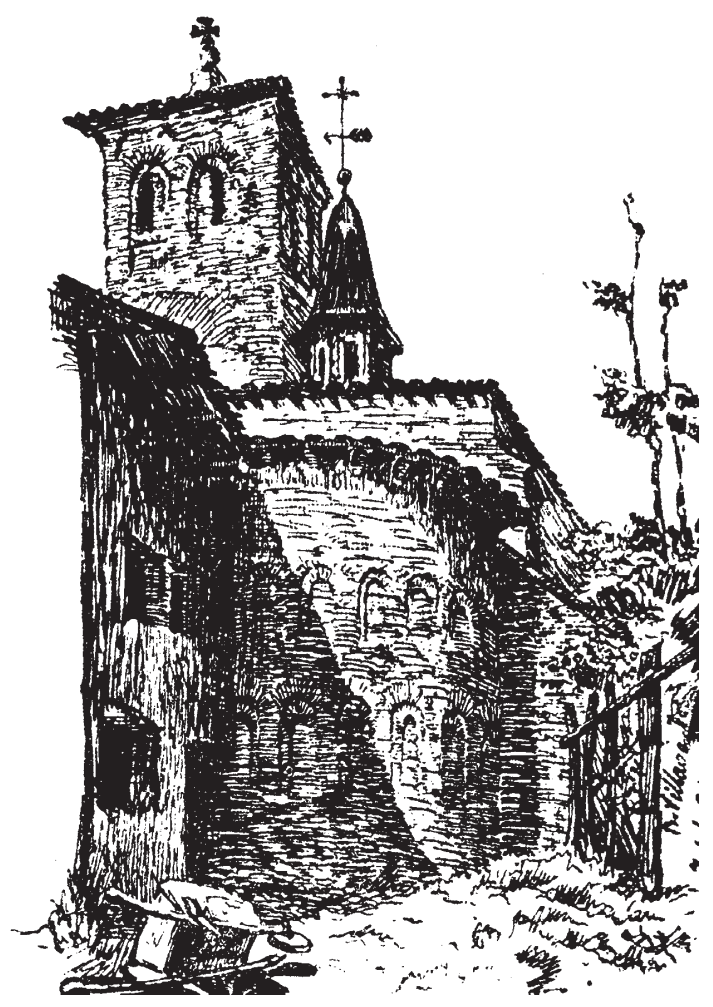

Fig. 4. Dibujo de Bienvenido Villaverde (1896).

La planta representada corresponde al templo existente en ese momento. Esta era una Iglesia de una nave con capillas laterales, que en el lado del evangelio no llegan a los pies del templo. La iglesia se remata por medio de un ábside semicircular precedido de un presbiterio rectangular. A la derecha del presbiterio se sitúa la torre y la Capilla de los Orozco y en la izquierda la sacristía. En los pies del templo se representan dos soportes del coro alto. El acceso se hacía a través de la puerta situada a los pies, que iba precedida de un atrio.

Otros documentos gráficos no aportan datos sobre el estilo ni la traza de este edificio, sin embargo son importantes a la hora de situarlo dentro de la trama urbana de Guadalajara.

El primero, el más antiguo de los conservados de Guadalajara, representa de forma esquemática la Plaza Mayor y la de San Gil, con la Iglesia, precedida del atrio, y otros edifi$\operatorname{cios}^{11}$. El siguiente plano es un plano municipal de saneamiento y alineaciones. En él aparece reflejado el contorno de la Iglesia de San Gil y su atrio ${ }^{12}$.

$\mathrm{El}$ aspecto exterior lo conocemos gracias a un grabado realizado por Pascó ${ }^{13}$. En él se aprecia de forma parcial la fachada lateral derecha con sus huecos de iluminación de las capillas laterales, la torre y la linterna levantada sobre el presbiterio.

Una vista parecida, aunque más completa ya que comprende también la fachada principal, es la que tenemos gracias a una fotografía de Arquer.

Se conserva también un dibujo de no mucha calidad, realizado por Bienvenido Villaverde en 1896 que representa el ábside de la Iglesia visto desde un patio interior (fig. 4).

A pesar de que por la planta de Ibáñez Ibero conocemos que esta Iglesia antes de su demolición era de una nave con capillas laterales, el perfil que presentaba al exterior parecía indicar que en su origen fuese de tres naves, siguiendo el mismo esquema que otros templos de la época, con una nave central a dos aguas, cubierta probablemente por medio de una estructura de par y nudillo, y otras laterales a un agua con pendiente similar aunque a distinta cota que hace que sus faldones no sean continuación de los de la nave central.

Al frente se situaba un atrio que debido a la fuerte pendiente del terreno, como veremos en otras fotografías, se situaba sobre una plataforma. Esta fuerte pendiente es el motivo también de que no ocupe todo el frente de la Iglesia sino que se desplace hacia la derecha, quedando la puerta descentrada (fig. 5).

\footnotetext{
${ }^{11}$ Plaza Mayor e Iglesia de San Gil . 1792. Archivo Histórico Nacional (AHN).

12 Plano Municipal de 1864 de Saneamiento y Modificación de Alineaciones. Archivo Municipal de Guadalajara (AMG).

${ }^{13}$ Quadrado / De la Fuente, 1978: 45.
}

Arch. esp. arte, LXXXVIII, 350, ABRIL-JUNIO 2015, 113-130 ISSN: 0004-0428, eISSN: 1988-8511, doi: 10.3989/aearte.2015.07 


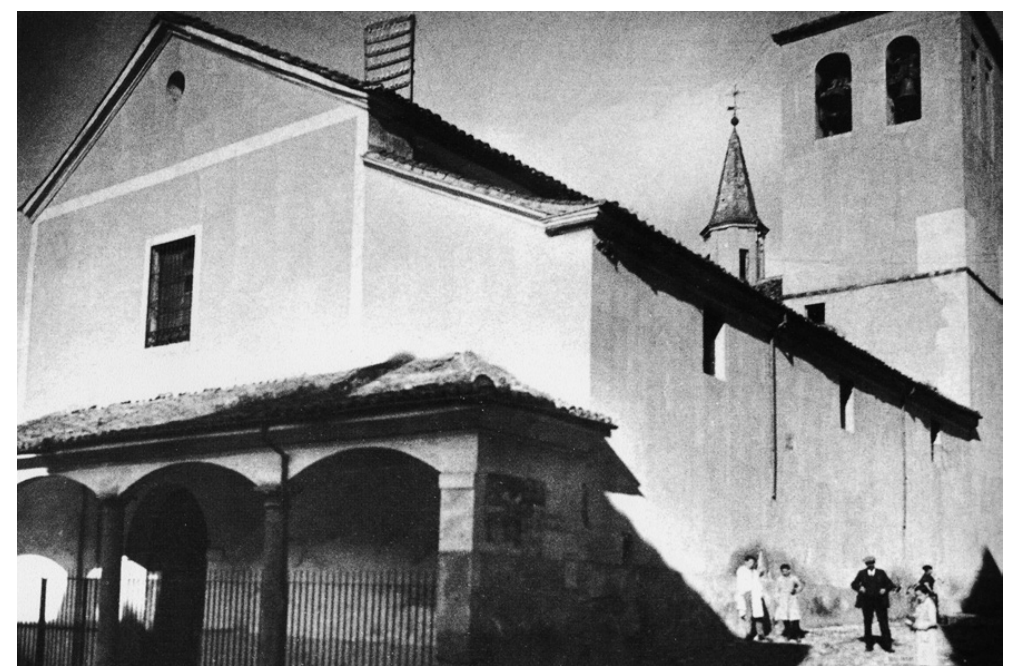

Fig. 5. Iglesia de San Gil.

Vista general.

Fotografía de Arquer.

Este atrio iba cerrado en los laterales y contaba con tres columnas (en la fotografía solo se aprecian dos), lo que dejaba cuatro vanos, correspondiendo el segundo por la izquierda a la puerta de entrada a la Iglesia.

Las columnas del atrio presentan capiteles toscanos, lo que indica que al igual que ocurrió con otras Iglesias como la de Santa María, este se levantó con posterioridad a la Iglesia, bien de nueva planta o bien para sustituir a otro anterior.

Superiormente los intercolumnios se cerraban por medio de unos falsos arcos. Probablemente, en su origen presentasen zapatas y carreras de madera y posteriormente con el fin de "enriquecer y modernizar" el edificio, se ejecutasen estos falsos arcos. El recurso de construir arcos "tapando" zapatas y carreras de madera también se empleó en otros edificios de la ciudad como ocurrió con el atrio de Santa María o en parte de las galerías arquitrabadas del claustro del desaparecido convento de San Bernardo ${ }^{14}$.

Como se ha indicado, en el atrio se situaba la puerta principal. Esta iba cerrada por medio de un arco de medio punto sin decoración, y presentaba como único motivo dos pequeñas impostas en el encuentro del arco y las jambas. El atrio estaba cerrado por medio de una verja de forja.

En la fotografía de Arquer se aprecia también la torre que presenta una imposta a media altura y una pequeña cornisa de remate y el lucernario de iluminación del presbiterio rematado con un puntiagudo chapitel. Exteriormente estaba totalmente revocada.

\section{Capilla de los Orozco}

Un elemento muy interesante de esta Iglesia era la Capilla de los Orozco, tanto por su sistema constructivo como por su decoración de yeserías.

Esta era una pequeña construcción de planta irregular que se aproximaba a un rectángulo, con muros perimetrales de ladrillo y mampostería de piedra caliza, cerrada superiormente por medio de una bóveda de cañón de ladrillo que se adosó a la cabecera del templo en el lado de la Epístola.

\footnotetext{
14 Trallero, 1998: 153-158, 205-216.

15 Sánchez, 1923.
}

Arch. esp. arte, LXXXVIII, 350, ABRIL-JUNIO 2015, 113-130 


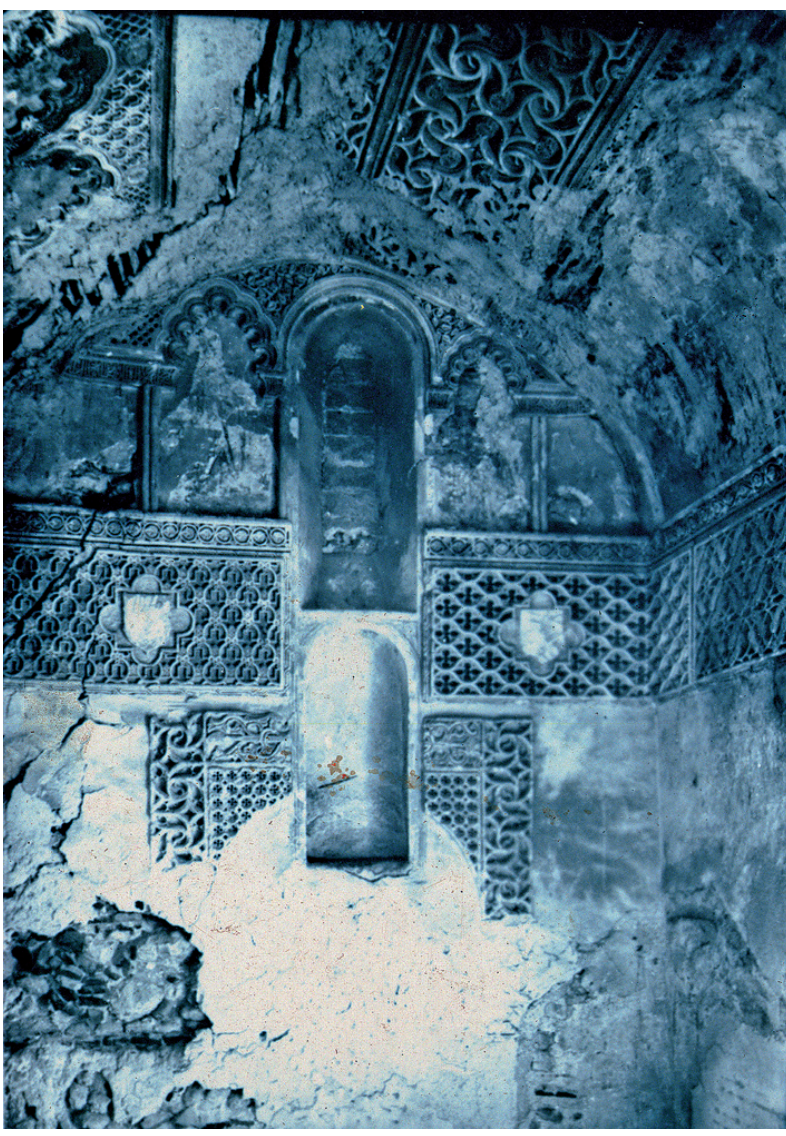

Fig. 6. Iglesia de San Gil. Capilla de los Orozco. Decoración interior. Foto Reyes.
José A. Sánchez Pérez, en su artículo Una estancia mudéjar en Guadalajara señalaba su importancia, comparándolo con el poco interés que según él tenía la propia Iglesia de San Gil a la que se adosaba, ${ }^{15}$ y hacía referencia a José M. Quadrado quién la consideraba anterior y la denominaba "capilla muzárabe de San Gil", apuntando la posibilidad de que se tratase de una edificación anterior que podría haber tenido un uso distinto al religioso. La fotografía aportada más adelante que corresponde a la demolición de esta capilla demuestra que su construcción es posterior a la de la Iglesia a la que se adosó (fig. 6).

Lo más llamativo de esta capilla era la decoración interior de medio de Yeserías, que cubrían gran parte de sus paramentos verticales y su bóveda.

Pavón Maldonado considera a estas yeserías como las más exquisitas de la provincia de Guadalajara y las fecha entre los últimos años del siglo XIV y los primeros del XV, vinculándola con el mudéjar toledano, especialmente con la Sinagoga del Tránsito, y con el sevillano de tradición almohade ${ }^{16}$.

\section{Proceso de demolición}

Unos documentos muy importantes para el conocimiento de esta Iglesia es la serie de fotografías que recoge su proceso de demolición iniciado tras el hundimiento del atrio, momento que es recogido por la primera de las fotografías. Solamente quedó en pie, aunque no aparece en la foto, el tramo de la derecha.

Se aprecia la plataforma sobre la que iba situado, la marca dejada por el muro que servía de cerramiento lateral y entre los escombros las basas de las columnas, vigas y las rejas.

En la marca dejada en el paramento de la nave de la Iglesia se ven los mechinales donde se empotraba la viguería del atrio. Su estructura estaba formada por una serie de pares inclinados, formando la pendiente de su cubierta, y otros horizontales que formaban el techo (fig. 7).

Al hundirse el atrio quedó al descubierto la parte del paramento comprendido entre el falso techo del atrio y el encuentro entre su cubierta y el muro, descubriéndose que este muro, en el que se encontraba la puerta de ingreso de medio punto, correspondía a la fábrica primitiva, habiéndose revocado y transformado la puerta de ingreso con posterioridad a la construcción del atrio hundido.

\footnotetext{
${ }^{16}$ Pavón, 1984: 41-42.
} 


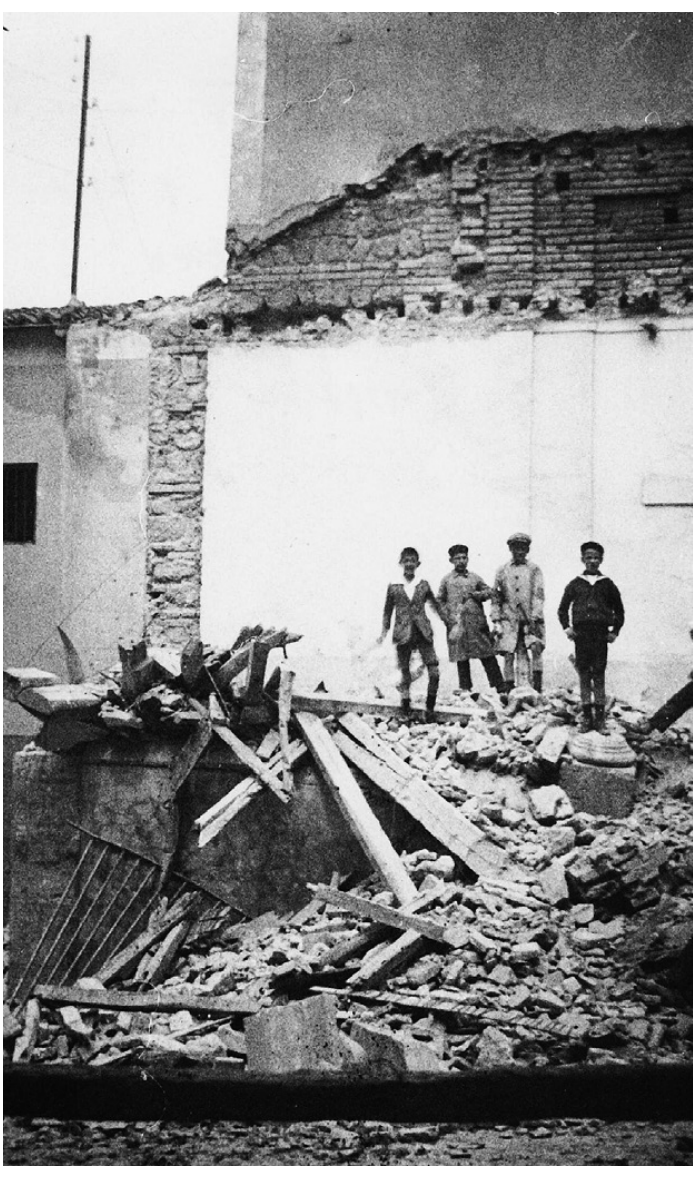

Fig. 7. Iglesia de San Gil. Demolición del atrio porticado.

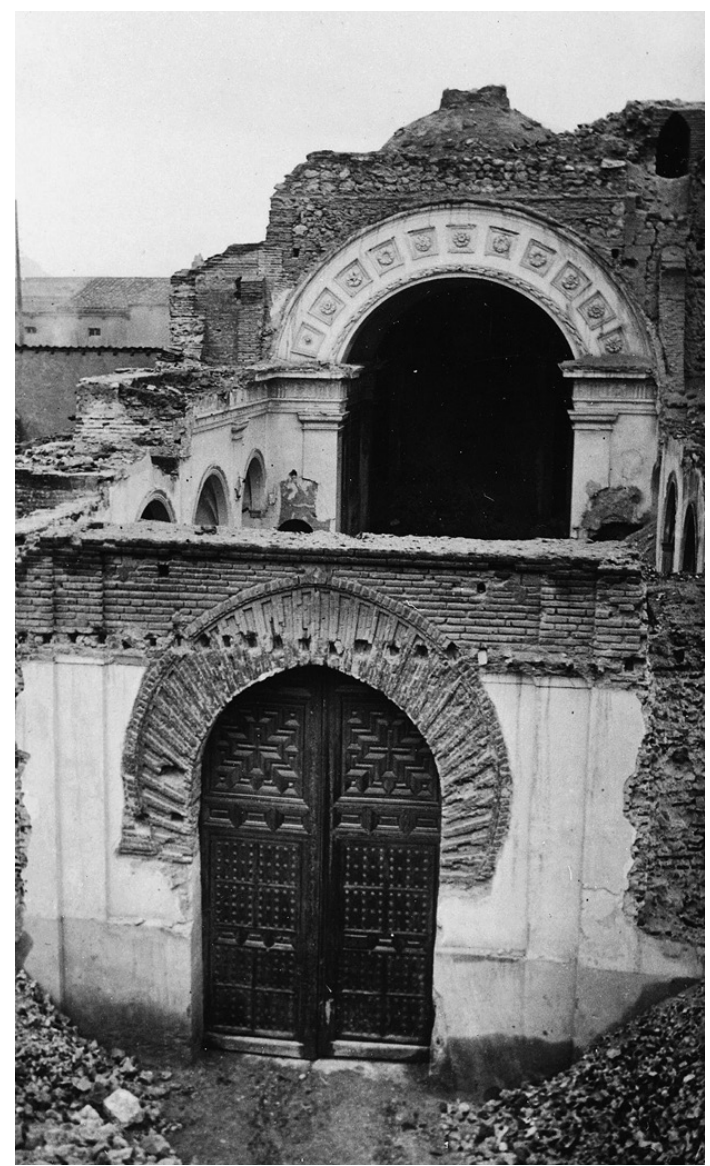

Fig. 8. Iglesia de San Gil. Proceso de demolición. Foto Goñi (AGA).

Tras este hundimiento se procedió a picar el resto del arco dejando al descubierto la puerta original, cuya traza guardaba muchas similitudes con las de la Iglesia de Santa María (fig. 8).

Ésta y otra fotografía recogen la fase de la demolición en la que se ha suprimido la cubierta, su estructura y parte de los muros de carga.

En la portada se aprecia que tras la parte puesta al descubierto tras la demolición del atrio, se procedió al picado del arco dejándolo al descubierto.

Esta fotografía permite ver el aspecto interior de la Iglesia, que era un templo de una nave con capillas laterales, tal y como se recoge en la planta del plano del Instituto Geográfico y Estadístico, separadas por pilastras clásicas sobre las que iba una cornisa que recorría horizontalmente toda la nave y que serviría de arranque a una bóveda de cañón, con arcos fajones, coincidiendo con las pilastras, y lunetos para iluminar el interior.

Un gran arco de triunfo, decorado con casetones, que también arrancaba de la cornisa perimetral, servía de separación de la nave y el presbiterio. La comunicación quedaba enmarcada por medio de dos pilastras.

Un elemento importante es la cúpula semiesférica que aparece en el presbiterio que se coronaba por medio de una linterna provista de un chapitel hexagonal revestido de pizarra (fig. 9).

Arch. esp. arte, LXXXVIII, 350, ABRIL-JUNIO 2015, 113-130

ISSN: 0004-0428, eISSN: 1988-8511, doi: 10.3989/aearte.2015.07 


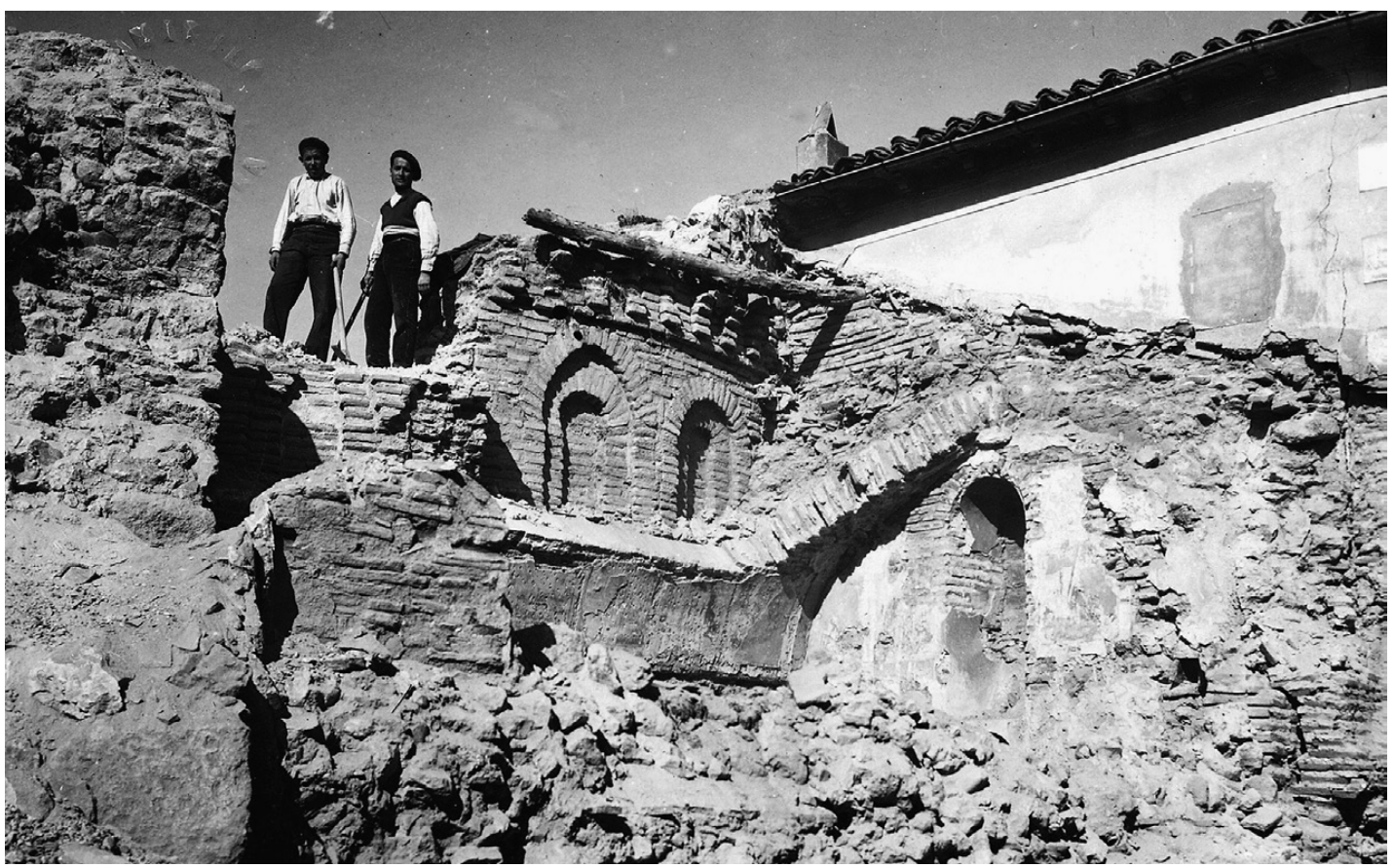

Fig. 9. Iglesia de San Gil. Demolición de la capilla de los Orozco. Foto Camarillo (BIG).

Esta fotografía recoge el proceso de demolición del ábside y la capilla de los Orozco, de la que ha desaparecido la bóveda de cañón que la cerraba superiormente. Se aprecia claramente, por la aparición de los arcos ciegos del ábside, como esta capilla se adosó al ábside previamente existente y no al revés. También aparece la construcción que con posterioridad se adosó a la Iglesia utilizando su propia estructura (muros), es decir, apoyando directamente sobre ella, lo que determinó la conservación del ábside.

Estas fotografías, además de mostrarnos el aspecto que presentaba la Iglesia en el momento de su demolición, nos muestra también algunos detalles fundamentales para conocer su fábrica primitiva. Ya se ha visto, que gracias a la demolición del atrio, se comprobó que el muro de los pies y su puerta principal correspondía al templo mudéjar primitivo, y que posteriormente se había transformado, eliminando el alfiz, y el dovelaje, e incluso trasformado el arco apuntado en uno de medio punto.

En la fotografía siguiente se aprecia además que sobre los muros que sirven de cierre a las capillas laterales, en la zona de contacto con la cabecera, existen unos arranques de unos arcos que dan a entender que se trata de la fábrica primitiva, transformada posteriormente, como veremos más adelante

Es muy interesante el informe emitido por D. José Ramón Mélida tras la declaración del edificio como Monumento Histórico Artístico (22 de Agosto de 1924) ${ }^{17}$. Al amenazar ruina el edificio se pidió con carácter de urgencia a la Academia un informe previo a su completa demolición.

En el informe se dice "Hay indicios de que la Iglesia de San Gil, en Guadalajara, debió ser construcción estimable, realizada por los siglos XIV o XV; pero reconstruida en el siglo XVII, tan

${ }^{17}$ Informe sobre la iglesia de San Gil, de Guadalajara. José Ramón Mélida y Alinari. Real Academia de Bellas Artes de San Fernando. Comisión de Monumentos Exp. CAGU/9/7956/19(5).

Arch. esp. arte, LXXXVIII, 350, ABRIL-JUNIO 2015, 113-130 ISSN: 0004-0428, eISSN: 1988-8511, doi: 10.3989/aearte.2015.07 
solo quedaron de la fabrica primitiva la portada principal y una capilla adosada al ábside, desfiguradas al hacer dicha obra y ambas de gusto mudéjar"

La afirmación es tajante, al mismo tiempo que, como veremos más adelante, errónea. Según Mélida el templo del XIV o XV se demolió conservando únicamente una capilla adosada al ábside (Capilla de los Orozco) y la portada principal. Mélida incluye la portada ya que en ese momento, tras el hundimiento del atrio se había descubierto. De no haber sido así, probablemente habría considerado que del templo primitivo solo se había conservado la Capilla de los Orozco.

Mélida no hace referencia al ábside como parte del templo primitivo, elemento que era visible desde un patio interior como se muestra en el dibujo de Bienvenido Villaverde de 1896, que se puede deducir de la planta del plano del Instituto Geográfico y Estadístico y por lo tanto, desde el interior se podía intuir, y más tarde, tras la demolición de la capilla de los Orozco, se pudo comprobar.

Desde mi punto de vista, considero que el informe fue redactado sin conocer el edificio con la profundidad suficiente. Se incluye el interés de la capilla porque según él era el único elemento que su estructura y decoración manifestaban claramente su origen medieval, y se menciona la portada gracias a que tras el hundimiento del atrio quedó al descubierto parte de la fábrica, lo que determinó que se descubriese toda la portada poniendo de manifiesto una puerta similar a las conservadas en la Iglesia de Santa María.

De la capilla, hace referencia a su "bella exornación mudéjar de estilo toledano" y de la portada que "Del mismo género es la portada de ladrillo" planteando su conservación, aunque posteriormente corrige e indica que es "susceptible de ser transportada y reconstruida".

Concluye diciendo que puede autorizarse el derribo de la iglesia proponiendo la reconstrucción de la portada "en otro sitio" y la conservación de la capilla.

La Real Academia de Bellas Artes de San Fernando, en la sesión celebrada el 20 de Octubre de 1924, tras un examen "de visu" del edificio acordó hacer suyo el informe emitido previamente por Sentenach ${ }^{18}$ en el que proponía modificar la declaración de monumento de la Iglesia limitándola únicamente la capilla y a la portada, informe en el que aparte de limitar el interés de edificio a estos dos elementos, justifica por razones constructivas su demolición, y por razones factibles la conservación de los elementos propuestos.

La prensa de la época se hizo eco del arco aparecido tras el hundimiento del atrio, recogiendo el trazado realizado por los alumnos del Institutito de Segunda Enseñanza, como práctica.

Este mismo semanario, meses después, recogía mediante un dibujo "lo que podía ser la Plaza de San Gil, gastando en ello unas diez mil pesetas ",19.

\section{Levantamiento de la Iglesia}

D. Fernando de la Vega Todolí ha realizado bajo mi dirección el levantamiento de los planos que representan a la Iglesia de San Gil antes de su demolición.

Para la planta se ha reproducido la realizada por el Instituto Geográfico y Estadístico, en la que aparecen reflejadas algunas de sus dimensiones, así como los usos de cada una de las dependencias. También ha servido de documentación de partida el levantamiento realizado de los restos conservados, muros del ábside, sacristía y capilla de los Orozco.

Para el resto de las vistas, alzados, secciones y detalles, se han utilizado el resto de los documentos conservados, planos, dibujos y sobre todo el reportaje fotográfico del proceso de demolición (figs. 10, 11 y 12).

\footnotetext{
${ }^{18}$ Sentenach, 1924: 163-164.

19 "Semanario Renovación" 6-VIII-1926; 15-X-1926.
}

Arch. esp. arte, LXXXVIII, 350, ABRIL-JUNIO 2015, 113-130

ISSN: 0004-0428, eISSN: 1988-8511, doi: 10.3989/aearte.2015.07 


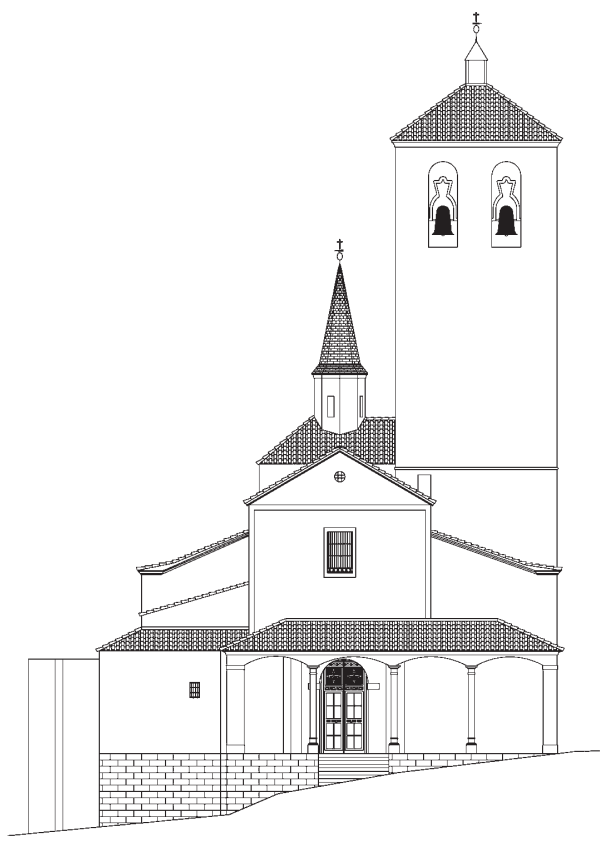

Fig. 10. Iglesia de San Gil. Alzado frontal. Fernando de la Vega Todolí con la dirección de Antonio M. Trallero.

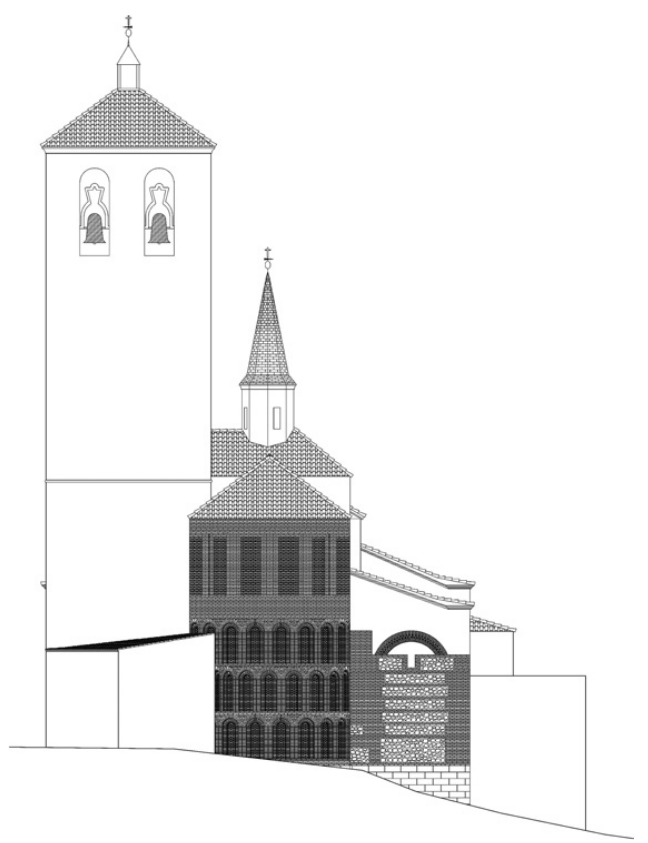

Fig. 11. Iglesia de San Gil. Alzado posterior. Fernando de la Vega Todolí con la dirección de Antonio M. Trallero.

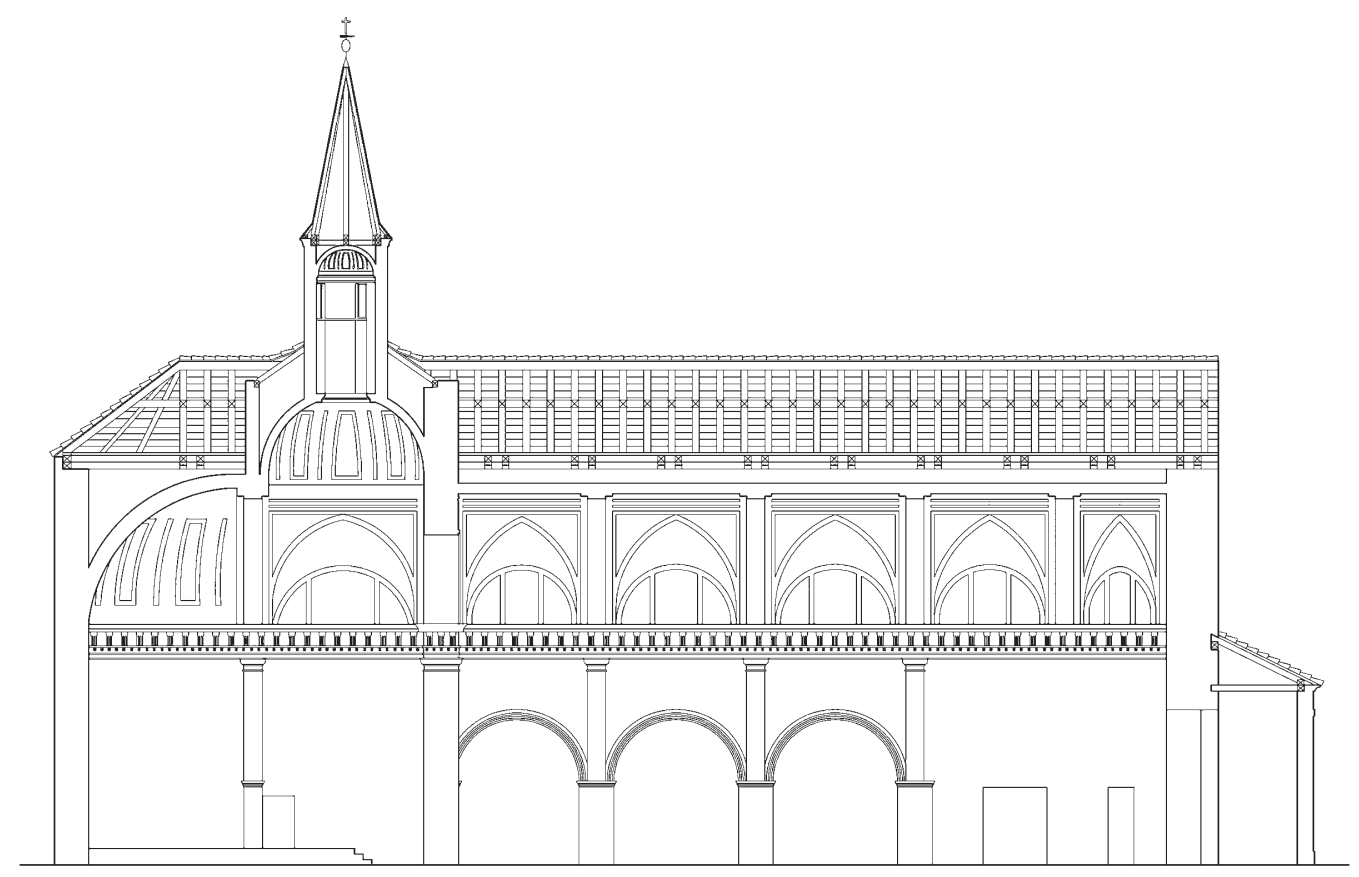

Fig. 12. Iglesia de San Gil. Sección longitudinal. Fernando de la Vega Todolí con la dirección de Antonio M. Trallero.

Arch. esp. arte, LXXXVIII, 350, ABRIL-JUNIO 2015, 113-130 ISSN: 0004-0428, eISSN: 1988-8511, doi: 10.3989/aearte.2015.07 


\section{Aproximación a la Iglesia de San Gil}

Varios autores como Pedro Pradillo Esteban ${ }^{20}$ y José Sánchez de Castro ${ }^{21}$ han tratado de realizar en sus estudios unas recreaciones del templo desaparecido. La presente aproximación se basa fundamentalmente de la interpretación de la documentación gráfica existente.

\section{El templo demolido}

Antes de su demolición, la imagen de la Iglesia de San Gil era la de un templo Barroco, siendo identificable como "mudéjar" únicamente la capilla de los Orozco, cerrada superiormente por medio de una bóveda de cañón, decorada interiormente por medio de yeserías mudéjares, ya que su ábside estaba ocupado por edificaciones quedando libre únicamente una parte que solo era visible desde los corrales las fincas colindantes, lo que hizo que pasara desapercibido a José Mélida y a Narciso Sentenach.

Interiormente era un templo de una nave con capillas laterales, que en el lado de la Epístola ocupaban toda la longitud de la Iglesia, mientras que en el lado del Evangelio, junto a los pies del templo, existían unos "locales para enseres", así como un paso al patio lateral localizado entre dos capillas. Esto determinaba una falta de simetría en el alzado frontal.

Como ha quedado indicado, en la nave central el ritmo interior lo marcaban unas pilastras clásicas sobre las que iba colocada una cornisa con triglifos. Superiormente iba cerrada por medio de una bóveda de cañón con arcos fajones y lunetos. Las capillas laterales, con decoración similar al de la nave central, irían cubiertas por medio de bóvedas de arista.

A los pies de la nave existía un coro alto, apoyado sobre dos pilares, al que se accedía por medio de una escalera.

Frontalmente contaba con un gran arco decorado con rosetones que separaba a la nave central del presbiterio, que iba cubierto por medio de una cúpula rematada superiormente por medio de un lucernario en forma de aguja. Los paramentos laterales contaban con pilastras y cornisa similar a la de la nave central. Este espacio se cerraba por medio del ábside que contaba con el mismo tipo de decoración.

Desde el ábside se accedía por la derecha a la capilla de los Orozco y desde ella a la torre.

Por la izquierda del ábside, se accedía a la sacristía, y desde ella al patio lateral.

Exteriormente todo el templo iba revestido de mortero, únicamente una parte del ábside que no era visible desde el exterior, conservaba su decoración. Las capillas laterales se iluminaban por medio de unos huecos rectangulares, similares al que existía a los pies para iluminar la nave central.

La puerta de acceso era de medio punto con dos pequeñas impostas en los arranques del arco.

Exteriormente la torre iba revestida de manera similar al resto de las fachadas. Las campanas se alojaban en unos huecos cerrados superiormente por medio de arcos de medio punto sin decoración.

A los pies de la Iglesia, como se ha indicado, existía un atrio cerrado lateralmente por medio de dos muros y frontalmente presentaba tres columnas toscanas cerradas superiormente por medio de arcos rebajados.

\section{El atrio y el muro de los pies de la Iglesia}

El atrio de los pies de la Iglesia probablemente se levantó en el siglo XVI, de nueva planta o en sustitución de uno preexistente, siguiendo el esquema constructivo del patio renacentista

\footnotetext{
${ }^{20}$ Pradillo, 1994: 211-246.

${ }^{21}$ Sánchez, 1985: 145-155.
}

Arch. esp. arte, LXXXVIII, 350, ABRIL-JUNIO 2015, 113-130

ISSN: 0004-0428, eISSN: 1988-8511, doi: 10.3989/aearte.2015.07 
alcarreño ${ }^{22}$, es decir, con columnas de piedra sobre las que se colocaban unas zapatas de madera y sobre ellas una carrera también de madera. Posteriormente este atrio fue "barroquizado" probablemente al tiempo que el resto de la Iglesia, construyendo unos falsos arcos que ocultaban zapatas y carrera.

La estructura horizontal del atrio lo formaban unos pares inclinados que servían de apoyo al tejado, y unas viguetas horizontales con tablero para formar el techo de este espacio.

La demolición de este atrio dejó al descubierto parte del paramento original del muro de fachada, pudiéndose comprobar que éste formaba parte de la construcción original y que el hueco de entrada, la puerta principal, se conservaba prácticamente intacta.

Esto hizo que José Ramón Mélida en su informe, redactado tras el hundimiento del atrio pero con anterioridad a la demolición del resto de la Iglesia, dijera que esta Iglesia fue reconstruida en el siglo XVII y que de la antigua fábrica únicamente quedaron "la primitiva portada principal y una capilla adosada al ábside". Como se ha apuntado anteriormente, probablemente si el informe se hubiera redactado antes de la demolición del atrio, únicamente se habría referido a la capilla.

\section{El ábside y presbiterio}

A pesar de que el informe de Mélida no incluyera a la cabecera del templo como parte de su fábrica primitiva, los restos que se han conservado del ábside corresponden a una edificación mudéjar de tradición románica.

Como se puede ver en la planta del la Iglesia del Instituto Geográfico y Estadístico, el ábside iba precedido de un presbiterio de planta cuadrada. Por razones constructivas y estructurales el ábside iría cubierto por medio de una bóveda de cuarto de esfera, no gallonada (nervada) como propone José Sánchez de Castro ${ }^{23}$ y el presbiterio por medio de una de medio cañón. En la transformación del templo se sustituyó la bóveda de cañón por una media naranja con lucernario, mucho más acorde con la nueva imagen del resto del edificio, marcando un inexistente crucero.

\section{La torre}

Con respecto a la torre, en la representación del Instituto Geográfico y Estadístico aparece como un cuerpo prismático sin núcleo central.

Si comparamos esta planta con la de la torre de la Iglesia de Santa María, vemos que su representación es similar, contando ambas con un núcleo central "hueco", sin embargo, la torre de Santa María cuenta con un núcleo macizo, por lo que es posible que en ambas plantas se haya cometido el mismo error ${ }^{24}$.

Por otro lado, en la fotografía de Arquer se puede ver que los huecos de la torre, por lo menos en uno de sus lados, se abrían dentro de unos rectángulos, en un plano ligeramente rehundido con respecto al plano exterior que podría ser el alfiz de los huecos primitivos, y a media altura era rodeada por medio de una línea de imposta, una composición similar a la de la torre mudéjar de Santa María, lo que me lleva pensar que también la torre formaba parte de la edificación primitiva.

Sánchez de Castro la considera románica del siglo XIII indicando que permaneció en pie hasta 1940-1941 ${ }^{25}$, lo que no coincide con el reportaje fotográfico de la demolición.

\footnotetext{
22 Trallero: 1998.

${ }^{23}$ Sánchez: 1985: 153.

${ }^{24}$ Trabajos Topográficos. Guadalajara, 1878. Instituto Geográfico Nacional (IGN).

${ }^{25}$ Sánchez, 1985: 152.
} 


\section{La nave de la Iglesia}

Ya se ha descrito la traza de la nave del templo y de sus capillas laterales. En las fotografías correspondientes al proceso de demolición se pueden ver los arranques de unos arcos junto al muro del presbiterio que no tienen ninguna justificación constructiva en una Iglesia de una nave con capillas laterales, lo que lleva a pensar que tampoco la nave del templo fue demolida y posteriormente reconstruida, sino únicamente transformada siguiendo un proceso similar al sufrido en la Iglesia de Santa María ${ }^{26}$ en la que bajo la armadura de par y nudillo de su nave central y bajo las de colgadizo de las laterales se construyeron bóvedas barrocas, pudiendo en la actualidad verse recorriendo el trasdós de dichas bóvedas.

De esta manera, tendríamos una iglesia de tres naves, la central iría cubierta por medio de una estructura de par y nudillo y las laterales por estructuras de colgadizo.

Mientras que en Santa María se mantuvieron las tres naves, en San Gil las laterales se transformaron en capillas, bien por su poca anchura, o bien por su reducción debida a la modificación de la alineación exterior ${ }^{27}$.

En el lado del Evangelio, en la zona de mayor desnivel del terreno natural, se aprecia que la anchura de las capillas es menor que en el lado de la Epístola. Esto unido a que las capillas laterales no ocupan todo el lateral, quedando unas dependencias auxiliares, una capilla con distinta estructura y un paso al patio posterior, podría indicar que ésta zona fue totalmente reconstruida.

José Sánchez de Castro ${ }^{28}$, hace referencia a una puerta meridional con arco de herradura, que no aparece reflejada en el plano del Instituto Geográfico ni en la fotografía de Anquer ni en los informes de Mélida y Sentenach, lo que contradice a la modificación de alineación indicada por Pradillo. De cualquier forma, en el caso de haber existido, habría aparecido en el proceso de demolición embebida en el muro lateral derecho, puerta que tendría justificación en un templo de tres naves.

\section{Conclusiones}

Como conclusión cabe decir que el antiguo templo parroquial de San Gil en Guadalajara, demolido en el año 1924 tras haber sido declarado Monumento Histórico Artístico, no era una edificación construida en el siglo XVII tras la demolición de un edificio preexistente del que se había únicamente conservado una capilla adosada y la puerta de ingreso, sino que en el siglo XVII lo que se llevó a cabo fue una profunda transformación de la edificación primitiva, muy relacionada con la que sufrió también la Iglesia Parroquial de Santa María, con la que guarda muchas similitudes. Estas modificaciones, aunque pudo haber habido alguna reconstrucción parcial, consistieron básicamente en la construcción de unas bóvedas interiores bajo las estructuras mudéjares, transformando las tres naves en una nave única con capillas laterales.

En el presbiterio se sustituyó la bóveda de cañón por una semiesférica con linterna.

Exteriormente se construyeron unos falsos arcos en el atrio y se revocó toda la fachada privando al edificio de toda su decoración original.

\footnotetext{
${ }^{26}$ Mejía, 2010: 78-99.

27 Pradillo, 1994: 221.

28 Sánchez, 1985: 152.
}

Arch. esp. arte, LXXXVIII, 350, ABRIL-JUNIO 2015, 113-130

ISSN: 0004-0428, eISSN: 1988-8511, doi: 10.3989/aearte.2015.07 


\section{BIBLIOGRAFÍA}

Abril Peiró, A. (2001): Tomás Camarillo. Los ojos de Guadalajara. Guadalajara: Ediciones y publicaciones Guadalajara 2000 S. A.

Azcárate Ristori, J. Ma . (1983): Inventario artístico de Guadalajara y su provincia. Madrid: Centro Nacional de Información Artística, Arqueológica y Etnológica.

Baldellou, M. A. (1989): Tradición y cambio en la arquitectura de Guadalajara (1850-1936). Guadalajara: Colegio Oficial de Arquitectos de Castilla la Mancha.

Barbe-Coquelin de Lisle, G. (1985): Historia de la Arquitectura Española. Tomo 2 Arquitectura Mudéjar. Barcelona: Editorial Planeta, pp. 689-747.

Baldominos Utrill, Rosario / Esteban Prendas, Montserrat (1985): "La Iglesia de Aldeanueva de Guadalajara, un monumento de síntesis con pluralidad de funciones”. En: Revista de Estudios Wal-Al-Hayara, No 12. Guadalajara: Institución Provincial de Cultura "Marqués de Santillana" Diputación Provincial de Guadalajara, pp. 123-143.

Borrás Gualis, Gonzalo (1987): “A propósito de arquitectura de ladrillo y arquitectura mudéjar”. En: Artigrama. $\mathrm{N}^{0}$ 4. Zaragoza, pp. 25-34.

Caamaño Martínez, J. M. (1985): Historia de la Arquitectura Española. Tomo 2 Arquitectura Hispanomusulmana. Barcelona: Editorial Planeta, pp. 749-815.

Cabrera Pérez, A. (2000): Guadalajara, el lápiz de la luz. Toledo: JCCM.

Catalina García López, J. (1911): Catálogo Monumental de Guadalajara I y II. Madrid: Ministerio de Fomento.

Catalina García López, J. (1973): La Alcarria en los dos primeros siglos de su Reconquista. Guadalajara. Guadalajara: Institución Provincial de Cultura "Marqués de Santillana". Diputación Provincial de Guadalajara.

Catalina García López, J. (2003). Relaciones topográficas de España. Provincia de Guadalajara. Guadalajara: 2003. AACHE (CD).

Cuadrado Prieto, M. A. / Crespo Cano, M. L. / Arenas Esteban, J. A. (2001): "Madinat al-Faray: El Alcázar y la formación de una ciudad islámica". En: Actas del VII Encuentro de Historiadores del Valle del Henares Guadalajara, pp. 87-96.

Delgado Valero, C. y Pérez Higuera, T. (1991): Arquitecturas de Toledo. El período islámico y mudéjar. Toledo: JCCM.

García Ballesteros, Aurora (1978): Geografía urbana de Guadalajara. Madrid: Fundación Universitaria Española.

Gaya Nuño, A. (1961): La arquitectura española en sus monumentos desaparecidos. Madrid: Espasa Calpe.

Lampérez Romea, V. (1999): Historia de la arquitectura cristiana española en la Edad Media. Valladolid: Ámbito.

Laredo Quesada, M. A. (1981): Los mudéjares de Castilla en la Baja Edad Media. En: Actas del I Simposio Internacional de Mudejarismo. Teruel.

Lavado Paradinas, P. J. (1990): Arte mudéjar en la cuenca del Henares. En: Actas del II Encuentro de historiadores del Valle del Henares. Alcalá de Henares.

Layna Serrano, F. (1941): Historia de Guadalajara y sus Mendozas en los siglos XV y XVI. Madrid: Consejo Superior de Investigaciones Científicas.

Layna Serrano, F. (1943): Los Conventos antiguos de Guadalajara. Madrid: Consejo Superior de Investigaciones Científicas.

López Mondéjar, P. (2005): La Huella de la Mirada. Fotografía y Sociedad en Castilla-La Mancha 18391936. Barcelona: Editorial LUNWERG.

Martos Causapié, J. F. / Ruiz Rojo, J. A. (2007): La Fotografia en la prensa antigua de Guadalajara (18911929). Guadalajara: Diputación Provincial de Guadalajara.

Martos Causapié, J. F. / Ruiz Rojo, J. A. (2009): La Fotografía Estereoscópica en Guadalajara. Guadalajara: Diputación Provincial de Guadalajara.

Martínez Caviró, B. (1980): Mudéjar toledano, palacios y conventos. Madrid: D. L.

Mejía Asensio, A. (2010): Santa María de la Fuente. Guadalajara: Patronato de Cultura del Ayuntamiento de Guadalajara.

Arch. esp. arte, LXXXVIII, 350, ABRIL-JUNIO 2015, 113-130 ISSN: 0004-0428, eISSN: 1988-8511, doi: 10.3989/aearte.2015.07 
Montoya Invarato, R. (1973): Sobre los ábsides mudéjares toledanos y su sistema de trazado. Madrid: AlAndalus, CSIC.

Núñez de Castro, A. (2003): Historia eclesiástica y seglar de la muy noble y muy leal ciudad de Guadalajara. (facsímil de 1653). Guadalajara: Editorial AACHE.

Ortiz García, A. (coord.) (1996): Los Fueros de Guadalajara. Guadalajara: Ayuntamiento de Guadalajara.

Pavón Maldonado, B. (1984): Guadalajara medieval. Arte y Arqueología árabe y mudéjar. Madrid: CSIC. Instituto Miguel Asín.

Pavón Maldonado, B. (1981): Arte islámico y mudéjar en Toledo. En: Al-qantara: Revista de estudios árabes. Madrid: CSIC.

Pérez Higuera, M. Teresa (1987): Mudejarismo en la Baja Edad Media. Madrid: La Muralla.

Pérez Higuera, M. Teresa (1985): “Arquitectura mudéjar en los antiguos reinos de Castilla, León y Toledo". En: Borrás Gualis, G. (1985): El arte mudéjar. Zaragoza: Ediciones UNESCO-IberCaja.

Pradillo y Esteban, Pedro José (1994): "La desaparecida parroquia de San Gil de Guadalajara: Estado de la cuestión y nuevas aportaciones”. En: Revista de Estudios Wad-Al-Hayara, número 21. Guadalajara: Institución Provincial de Cultura "Marqués de Santillana" de Guadalajara. Diputación Provincial de Guadalajara, pp. 211-256.

Quadrado, J. M․ / De La Fuente, V. (1978): España, sus monumentos y artes, su naturaleza e historia: Castilla la Nueva, Guadalajara y Cuenca. Barcelona: Ediciones El Albir.

Ruiz Rojo, J. A. / Pradillo y Esteban, P. J. / Martos Causapié, J. F. / González Gascón, A. (2004): Tesoros fotográficos de Guadalajara. Guadalajara: Diputación de Guadalajara / CEFIHGU.

José Sánchez de Castro, José (1985): "Mudejarismo en Guadalajara (siglos XIII-XV)". En: Wad-al-Hayara, 12. Guadalajara: Institución Provincial de Cultura "Marqués de Santillana" de Guadalajara. Diputación Provincial de Guadalajara, pp. 211-256.

Sánchez Pérez, J. A. (1923): "Una estancia mudéjar en Guadalajara”. En: Boletín de la Real Academia de la Historia.

Sentenach, Narciso (1924): "Informe acerca de declaración de Monumento Nacional del que es Arquitectónico-Artístico de la estancia mudéjar adosada a la Iglesia de San Gil de Guadalajara”. En: BASF. Cuarto Trimestre, Núm.72, pp.163-164.

Torres Balbás, L. (1949): Arte almohade - arte nazarí-arte mudéjar. (Ars Hispaniae, IV). Madrid: Espasa Calpe.

Trallero de Lucas, C. / Sánchez Jabonero, R. / García Quemada, A. / Mediano San Andrés, N. / Trallero Sanz, A. M. (2011): De Santo Tomé a Nuestra Señora de la Antigua. Guadalajara: Patronato de Cultura del Ayuntamiento de Guadalajara.

Trallero Sanz, A. M. (1998): El patio renacentista alcarreño. Zaragoza: Ibercaja.

Valdés Fernández, M. (1999): “Arte hispanomusulmán, albañilería románica y arquitectura mudéjar en los reinos de Castilla y León”. En: Actas del Congreso Internacional sobre restauración del ladrillo Sahagún (León), pp. 25-36.

Valdés Fernández, M. (2010): “Arquitectura Mudéjar o arquitectura medieval de ladrillo: un debate académico”. En: Borras Gualis, G.: Mudéjar, el legado andalusí en la cultura española Zaragoza: Universidad de Zaragoza.

Fecha de recepción: 09-XII-2013

Fecha de aceptación: 07-V-2014

Arch. esp. arte, LXXXVIII, 350, ABRIL-JUNIO 2015, 113-130

ISSN: 0004-0428, eISSN: 1988-8511, doi: 10.3989/aearte.2015.07 
